\title{
Desenvolvimento e validação do instrumento de compreensão de expressões idiomáticas
}

\section{Idioms comprehension instrument: development and validation}

\section{Maity Siqueira}

Universidade Federal do Rio Grande do Sul, Porto Alegre, Rio Grande do Sul / Brasil maity.siqueira@ufrgs.br

Daniela Fernandes Marques

Universidade Federal do Rio Grande do Sul, Porto Alegre, Rio Grande do Sul / Brasil daniemarques@hotmail.com

Resumo: As expressões idiomáticas são um tipo recorrente de linguagem figurada, fundamental para o entendimento de diferentes tipos de discurso. Este artigo o objetivo de apresentar o processo de desenvolvimento e de validação de um instrumento de compreensão de expressões idiomáticas. O trabalho foi desenvolvido pela perspectiva teórica da Linguística Cognitiva e estruturado conforme as seguintes etapas, consagradas em Psicometria: procedimentos teóricos, experimentais e analíticos. Foram consideradas as seguintes dimensões das expressões idiomáticas utilizadas nos itens: familiaridade, estrutura sintática, complexidade semântica e composicionalidade. A primeira foi verificada por meio de um teste psicolinguístico, e as outras foram controladas. $\mathrm{O}$ estudo resultou em uma nova ferramenta de avaliação da compreensão de linguagem figurada, que poderá ser utilizada com indivíduos de diferentes faixas etárias, de populações clínicas e não clínicas.

Palavras-chave: expressões idiomáticas; linguagem figurada; desenvolvimento de teste psicolinguístico; validação de teste psicolinguístico. 
Abstract: Idioms are a recurring type of figurative language, fundamental to the understanding of different discourse types. This article aims to present the development and validation process of an idiom comprehension test. The study was conducted considering the Cognitive Linguistics approach and was organized according to three well stablished steps in Psychometrics: theoretical, experimental and analytical procedures. The following dimensions of idioms were considered: familiarity, syntactic structure, semantic complexity and compositionality. The first was verified by a psycholinguistic test and the others were controlled. The study resulted in a new assessment tool of figurative language comprehension, which can be used with individuals from different age groups, in clinical and non-clinical populations.

Keywords: idioms; figurative language; psycholinguistics' development test; psycholinguistics validation test.

Recebido em 10 de dezembro de 2016.

Aceito em 21 de abril de 2017.

\section{Introdução}

A compreensão de expressões idiomáticas (EI), fenômeno da linguagem figurada, é frequente nas nossas trocas conversacionais diárias, em diversos tipos de discurso. A habilidade de compreender expressões figuradas, portanto, é fundamental para que uma pessoa se comunique bem. Considere uma situação em que um amigo diz para o outro "o meu vizinho bateu as botas". Um falante de português brasileiro que conheça os significados das palavras 'bater' e 'botas', não entenderá o significado idiomático da combinação dessas palavras, a menos que já tenha aprendido seu sentido figurado, que é 'morrer'. Uma vez que se conheça o significado de uma expressão, é fácil entender um enunciado que contenha esse tipo de expressão, tanto contextualizado quanto fora de contexto. Definir o que é uma expressão idiomática, no entanto, não é uma tarefa simples. Na literatura sobre EI são encontradas diferentes definições, norteadas por diversos enfoques teóricos.

As expressões idiomáticas têm sido tradicionalmente definidas como expressões linguísticas cujo significado não pode ser depreendido somente pela soma dos seus constituintes. Entretanto, reduzir o conceito 
de idiomaticidade ao de não composicionalidade, ou seja, à soma do significado dos itens lexicais, explica expressões opacas como bater as botas, mas não é suficiente para definir o fenômeno.

A Linguística Cognitiva sugere que outras dimensões, além da composicionalidade, contribuem para a compreensão de uma EI. Gibbs (1994) e Kövecses (2006) defendem a ideia de um continuum de significação e sustentam que as EI não são necessariamente arbitrárias e podem ser motivadas, indo de expressões bastante opacas (bater as botas) a outras mais transparentes (cozinhar em fogo brando). Em relação à arbitrariedade das EI, uma das maiores contribuições da Linguística Cognitiva para o estudo desse fenômeno linguístico, na verdade, foi chamar a atenção para o fato de que muitas EI são oriundas de mapeamentos conceituais metafóricos, ou seja, EI não são necessariamente aleatórias. As expressões idiomáticas soltar fogo pelas ventas e dar um gelo, assim como tantas outras expressões do português brasileiro, por exemplo, atualizam linguisticamente a metáfora conceitual INTENSIDADE DE EMOÇÃO É CALOR. Expressões oriundas de mapeamento conceituais como esse, de fato, podem apresentar um maior grau de transparência, o que pode ser explicado justamente pelo fato de atualizarem mapeamentos percebidos pelas pessoas (ainda que não necessariamente de modo consciente).

Nunberg, Sage Wasow (1994) afirmam que a definição tradicional é principalmente sintática e não contempla aspectos semânticos e pragmáticos do fenômeno. A esse respeito, Cacciari e Levorato (1989) afirmam que expressões idiomáticas, quando apresentadas dentro de um contexto, são mais bem compreendidas do que fora dele, uma vez que o contexto tem informações semânticas que auxiliam na inferência do significado apropriado das expressões. Cabe ressaltar que o contexto pode ser ainda mais importante para EI opacas e não familiares, das quais o significado não pode ser derivado somente da análise semântica das palavras que o compõe (CAIN; OAKHILL; LEMMON, 2005).

A definição operacional aqui adotada parte da perspectiva da Linguística Cognitiva e trata expressões idiomáticas como construções figuradas convencionalizadas, consideravelmente fixas com duas ou mais palavras, que têm uma função primariamente discursiva e que podem apresentar idiossincrasias (LANGLOTZ, 2006). Nessa perspectiva, Langlotz (2006) sistematiza as seguintes dimensões, que servem como parâmetro para a definição das expressões idiomáticas: o 
status gramatical (grau de convencionalização ou de familiaridade), a forma (complexidade, rigidez sintática, morfossintática e lexical de uma construção) e o significado (a não composicionalidade propriamente dita). Esse autor reforça a ideia de haver um continuum nos parâmetros de significação, uma vez que propõem que esses parâmetros podem estar mais ou menos presentes em determinadas EI. Talvez seja a grande variedade observada nesses parâmetros o que dificulta a elaboração de uma definição mais precisa e impede classificações estanques.

A operacionalização desses conceitos nas pesquisas experimentais encontradas sobre o tema tem sido feita com as expressões apresentadas aos participantes em diferentes formatos, em apresentações isoladas, em sentenças ou histórias. Diferentes pesquisadores utilizaram instrumentos com opções de respostas abertas e de múltipla-escolha - estas últimas na forma escrita ou pictórica. A escolha das EI levaram em conta parâmetros (ou combinações de parâmetros) tais como transparência e opacidade (NORBURY, 2004), familiaridade (KEMPLER; SIDTIS; MARCHMAN; BATES, 1999; QUALLS; LANTZ; PIETRZYK; BLOOD; HAMMER, 2004), familiaridade e opacidade (PAPAGNO; TABOSSI; COLOMBO; ZAMPETTI, 2004; PAPAGNO; CAPORALI, 2007), frequência (HILLERT, 2004) e contexto (CAIN; TOWSE; KNIGHT, 2009; CAIN; OAKHILL; LEMMON, 2005; LEVORATO; ROCH; NESI, 2007).

Embora a maioria dos estudos tenha referido o cuidado com aspectos citados anteriormente, nenhum deles referiu um cuidado com a validação dos itens antes de sua utilização. No Brasil, encontramos somente uma tarefa para avaliação de expressões idiomáticas, que compõe a Bateria Montreal de Avaliação da Comunicação (FONSECA; SALLES; PARENTE, 2008). Entretanto, nessa bateria, as expressões idiomáticas foram tratadas como metáforas, fenômenos que a Linguística Cognitiva diferencia. As EI utilizadas nos itens da Bateria MAC sob o rótulo de metáfora foram as seguintes: pôr a mão na massa, rodar a baiana, pisar em ovos, chorar sobre o leite derramado. Apesar de existirem instrumentos disponíveis em outras línguas, não há como simplesmente traduzir ou adaptar instrumentos que testem a compreensão de expressões idiomáticas, uma vez que qualquer tratamento dado ao fenômeno deve envolver considerações sobre língua e cultura. Além disso, é importante considerar variáveis como a frequência de uso das expressões idiomáticas averiguadas, a transparência dessas expressões e a diferenciação entre metáforas, metonímias, provérbios e expressões idiomáticas; e inclusão ou não de contexto. 
No intuito de possibilitar a avaliação de diferentes tipos de linguagem figurada, está sendo desenvolvido pelo grupo METAFOLIA, do PPG em Letras da UFRGS, o Teste de Compreensão de Linguagem Figurada, composto de tarefas de avaliação que incluem não só expressões idiomáticas, mas também metonímias, metáforas, provérbios e ironia. Uma vez que a linguística cognitiva enfatiza o caráter distinto de cada um desses fenômenos, entende-se que seja necessário avaliá-los separadamente. Este artigo trata exclusivamente da tarefa que envolve o fenômeno das expressões idiomáticas e apresenta as etapas de construção e validação do Instrumento de Compreensão de Expressões Idiomáticas, que fará parte do teste mais abrangente de compreensão da linguagem figurada.

Esse instrumento foi desenvolvido tendo como base um teste já validado, O Instrumento de Compreensão de Metáforas Primárias (SIQUEIRA, 2004), considerando o referencial teórico apresentado e seguindo etapas rigorosas já consagradas na área da psicometria, conforme o modelo proposto por Pasquali (2010), baseado em tarefas e métodos específicos que seguem uma ordem temporal pré-determinada e subsequente. O modelo é composto de três etapas distintas, denominadas procedimentos teóricos, empíricos ou experimentais e analíticos ou estatísticos, conforme descrito no Método, a seguir.

\section{Método}

\subsection{Participantes}

Esta pesquisa foi constituída por 557 participantes, selecionados por conveniência, considerando todas as fases de coleta de dados. A primeira fase, referente aos procedimentos teóricos, contou com 285 participantes $(m=31,7 ; d p=13,9)$. A amostra foi composta de alunos e funcionários da Universidade Federal do Rio Grande do Sul. Esses participantes preencheram uma escala Likert de familiaridade com as expressões idiomáticas elencadas para o estudo. O tamanho da amostra dessa primeira fase foi calculado considerando os seis itens pesquisados, supondo um percentual de familiaridade de no mínimo $70 \%$ na soma das categorias 4 (bastante familiar) e 5 (totalmente familiar) na escala (Anexo I) e uma margem de erro de 5\%.

A segunda fase, de realização do estudo piloto, contou com 10 participantes adultos ( $m=36,1$ e $d p=10,7)$. Já a terceira fase, de validação 
do instrumento, foi composta de 262 participantes, divididos em três grupos (132 crianças, 58 adolescentes e 72 adultos). As crianças tinham entre 5 anos e 11 anos e 11 meses $(m=7,4 ; d p=1,3)$, os adolescentes tinham entre 12 anos e 17 anos e 11 meses $(m=13,9 ; d p=1,4)$, e os adultos eram maiores de 18 anos $(m=41,6 ; d p=15,6)$. A linha de corte para a classificação etária foi feita conforme as diretrizes da American Academy of Pediatrics. A seleção da amostra e a coleta dos dados da segunda e terceira fases foram realizadas em escolas e universidades públicas e particulares do município de Porto Alegre. Os grupos de crianças e de adolescentes foram constituídos pelos alunos e o de adultos, pelos pais dos alunos das mesmas escolas, além de alunos e funcionários de uma universidade pública. Como critério de inclusão estabeleceu-se que os participantes deveriam ser falantes nativos de português brasileiro. $\mathrm{O}$ critério de exclusão foi a presença de comorbidades sensoriais e/ou cognitivas e de queixa de dificuldade de aprendizagem referidas pela escola, no caso de crianças e adolescentes.

\subsection{Procedimentos}

A construção do instrumento seguiu o modelo preconizado na área da psicometria por Pasquali (2010). Esse modelo é composto de três etapas distintas, denominadas (i) procedimentos teóricos, (ii) empíricos ou experimentais e (iii) analíticos ou estatísticos. Para realização dos procedimentos teóricos, o primeiro passo foi a definição do objeto de estudo e sua conceitualização, realizada por meio da pesquisa na literatura pertinente. Como o objeto de estudo em questão (a linguagem figurada) não pode ser medido diretamente, foi selecionado, com base em sua definição teórica (a perspectiva da Linguística Cognitiva) foi selecionado um atributo de interesse (a compreensão de expressões idiomáticas).

Ainda revisando a literatura, definiu-se que as expressões idiomáticas são caracterizadas pelas seguintes dimensões: familiaridade, estrutura sintática, complexidade semântica e composicionalidade. Entre essas dimensões, definiu-se que apenas a da familiaridade precisaria ser verificada para a elaboração dos itens, uma vez que todas as outras poderiam ser controladas. A estrutura sintática foi controlada por meio da elaboração de sentenças com as seguintes características: (i) apresentam estruturas simples, constituídas por somente uma oração; (ii) estão na voz ativa; (iii) seguem o modelo sujeito-verbo-objeto; (iv) são constituídas 
por sujeito formado por nomes próprios comuns; (v) têm núcleo do sujeito simples e (vi) têm o verbo (transitivo direto) na terceira pessoa do singular.

A complexidade semântica foi controlada pela seleção de palavras comuns da língua portuguesa. Todas as palavras utilizadas (por exemplo, gato, chá, tempestade, tomar, comprar e sair), além de bem conhecidas, são palavras facilmente entendidas. Por fim, o nível de composicionalidade foi controlado pela seleção de expressões idiomáticas não-composicionais. Uma evidência do caráter não-composicional das expressões selecionadas é o fato de nenhuma das sentenças utilizadas poder ser transformada em voz passiva sem perder o sentido figurado. Com base nessas dimensões, o construto pôde ser operacionalizado, ou seja, pôde ser transformado em itens mensuráveis.

Neste estudo, um outro aspecto controlado na seleção dos itens foi a existência de EI derivadas de metáforas conceituais. Partindo da ideia de que um mapeamento metafórico poderia facilitar a compreensão de uma EI - mesmo quando apresentada descontextualizada - só foram consideradas EI que, aparentemente, não são atualizações linguísticas de metáforas conceituais.

As possíveis expressões que constituiriam o instrumento foram selecionadas por meio de um brainstorming com sete integrantes do grupo de pesquisa das autoras do estudo. Entre essas expressões, foram pré-selecionadas seis para compor o instrumento, considerando o critério de frequência, as dimensões descritas em expressões não derivadas de metáforas conceituais. A frequência foi determinada pelo maior número de ocorrências encontradas em uma plataforma (Google) de busca na internet. Após essa pré-seleção, a fim de corroborar a pertinência dos itens na comunidade linguística, foi elaborada uma escala Likert de familiaridade. A escala continha as seis expressões, seguidas por cinco opções de escolha, em que 1 era "nada familiar" e 5 era "totalmente familiar".

Com base nisso, as expressões foram transformadas em sentenças. Para que tivessem sua compreensão facilitada, foi tomado não só o cuidado de utilizar palavras semanticamente simples, mas de parear gramaticalmente todas as sentenças para que tivessem a mesma estrutura e de compô-las com o menor número possível de palavras. Essas medidas foram observadas considerando possíveis aplicações futuras do instrumento em crianças pequenas e/ou em populações clínicas. Além disso, optou-se por selecionar expressões opacas, não composicionais 
e apresentá-las descontextualizadas, ou seja, em frases que não ajudam o participante a inferir o significado figurado das expressões. A frase Alice tomou um chá de cadeira, por exemplo, não remete ao fato de que ela esperou muito). Essa decisão metodológica de construir o item com sentenças fora de contexto foi tomada seguindo o modelo de Siqueira (2004) no Instrumento de Compreensão de Metáforas Primárias, já validado, que avalia outro tipo de linguagem figurada.

Ainda seguindo o modelo de Siqueira (2004), para cada item foi elaborada uma pergunta aberta e uma pergunta fechada. O uso de uma estrutura equivalente (em relação ao número de itens, ao tipo de sentença, ao tipo de perguntas feitas e à ausência de contexto) foi escolhido em razão de o primeiro instrumento, de compreensão de metáforas, apresentar evidências de validade na forma da avaliação. $\mathrm{O}$ fator determinante para essa escolha é que esse teste já está validado com populações clínicas (De LEON; SIQUEIRA; PARENTE; BOSA, 2007) e não clínicas (SIQUEIRA; LAMPRECHT, 2007), no Brasil e nos Estados Unidos (SIQUEIRA; GIBBS, 2007), com participantes de diferentes faixas etárias (crianças, adolescentes e adultos) e culturas (SIQUEIRA; PARENTE; GIL, 2009). Assumiu-se, portanto, que essa estrutura também seria adequada para avaliar a compreensão de expressões idiomáticas, um fenômeno afim às metáforas.

A análise de construto foi realizada por meio da apreciação de três juízes, especialistas na área. Os juízes receberam os itens juntamente com uma explicação sobre os objetivos do teste e um questionário para o julgamento do instrumento. No questionário, constavam perguntas sobre as dimensões do construto, ou seja, sobre a familiaridade, a estrutura sintática, as características semânticas, a composicionalidade das sentenças, bem como sobre a adequação das questões abertas e fechadas. Considerando-se observações dos juízes, as sentenças e as questões foram ajustadas e procedeu-se à aplicação do instrumento piloto.

Para verificar a validade aparente (a compreensão dos itens), essa versão do instrumento foi aplicada em dez participantes que representavam diferentes estratos (em termos de grau de escolaridade) da população-alvo. Subsequentemente, levando-se em conta aspectos reportados pelos aplicadores, foram feitos pequenos ajustes (tal como a eliminação de artigos definidos antes dos nomes próprios, no início das frases). Ao final dessa etapa, foi considerada concluída a elaboração do instrumento e realizada sua verificação no que se refere à validade de 
conteúdo. As seis expressões, as sentenças que constituem os itens, as perguntas e as diretrizes para sua correção estão descritas na Tabela 1.

\section{TABELA 1 - Instrumento de Compreensão de Expressões Idiomáticas e diretrizes para correção}

\begin{tabular}{|c|c|c|c|}
\hline EI & ITEM & PERGUNTAS & $\begin{array}{l}\text { DIRETRIZES PARA } \\
\text { CORREÇÃO }\end{array}$ \\
\hline $\begin{array}{l}\text { Fase de treino } \\
\text { X. Quebrar um } \\
\text { galho }\end{array}$ & $\begin{array}{l}\text { Luisa quebrou um } \\
\text { galho para a Carol. }\end{array}$ & $\begin{array}{l}\text { O que a Luisa fez para a Carol? } \\
\text { Ela ajudou ou atrapalhou a } \\
\text { Carol? }\end{array}$ & $\begin{array}{l}\text { a) Ajudou, fez algo que a } \\
\text { outra precisava ou queria. } \\
\text { b) Ajudou }\end{array}$ \\
\hline $\begin{array}{l}\text { 1. Comprar gato } \\
\text { por lebre. }\end{array}$ & $\begin{array}{l}\text { EI } 1 \\
\text { Antonio comprou } \\
\text { gato por lebre. }\end{array}$ & $\begin{array}{l}\text { a) Que aconteceu com ele? } \\
\text { b) Ele foi enganado ou não foi } \\
\text { enganado? }\end{array}$ & $\begin{array}{l}\text { a) Foi enganado, } \\
\text { trapaceado, passaram a } \\
\text { perna nele. } \\
\text { b) Compra ruim }\end{array}$ \\
\hline $\begin{array}{l}\text { 2. Meter os pés } \\
\text { pelas mãos. }\end{array}$ & $\begin{array}{l}\text { EI } 2 \\
\text { Cristina meteu os pés } \\
\text { pelas mãos. }\end{array}$ & $\begin{array}{l}\text { a) Como foi a atitude dela? } \\
\text { b) Ela pensou ou agiu sem } \\
\text { pensar? }\end{array}$ & $\begin{array}{l}\text { a) Impensada, afoita, ruim, } \\
\text { má, rápida demais. } \\
\text { b) Agiu sem pensar. }\end{array}$ \\
\hline $\begin{array}{l}\text { 3. Fazer } \\
\text { tempestade em } \\
\text { copo d'água. }\end{array}$ & $\begin{array}{l}\text { EI } 3 \\
\text { João fez tempestade } \\
\text { em copo d'água. }\end{array}$ & $\begin{array}{l}\text { a) Como ele reagiu? } \\
\text { b) Ele é preocupado ou } \\
\text { tranquilo? }\end{array}$ & $\begin{array}{l}\text { a) Mal, brabo, irritado, } \\
\text { furioso, se preocupou } \\
\text { demais. } \\
\text { b) Ficou preocupado. }\end{array}$ \\
\hline $\begin{array}{l}\text { 4. Sair como um } \\
\text { par de vasos. }\end{array}$ & $\begin{array}{l}\text { EI } 4 \\
\text { Ana e Lia saíram } \\
\text { como um par de } \\
\text { vasos. } \\
\end{array}$ & $\begin{array}{l}\text { a) Como elas se vestem? } \\
\text { b) As roupas delas são } \\
\text { diferentes ou iguais? }\end{array}$ & $\begin{array}{l}\text { a) Se vestem igual, da } \\
\text { mesma forma, com as } \\
\text { mesmas roupas. } \\
\text { b) Roupas são iguais. }\end{array}$ \\
\hline $\begin{array}{l}\text { 5. Ser a metade } \\
\text { da laranja. }\end{array}$ & $\begin{array}{l}\text { EI } 5 \\
\text { Paulo é a metade da } \\
\text { laranja da Laura. }\end{array}$ & $\begin{array}{l}\text { a) O que Laura sente por Paulo? } \\
\text { b) Ela adora ele ou detesta? }\end{array}$ & $\begin{array}{l}\text { a) Amor, paixão, gosta } \\
\text { dele. } \\
\text { b) Adora ele. }\end{array}$ \\
\hline $\begin{array}{l}\text { 6. Tomar um chá } \\
\text { de cadeira. }\end{array}$ & $\begin{array}{l}\text { EI } 6 \\
\text { Alice tomou um chá } \\
\text { de cadeira. }\end{array}$ & $\begin{array}{l}\text { a) O que aconteceu com Alice? } \\
\text { b) Ela esperou muito ou pouco? }\end{array}$ & $\begin{array}{l}\text { a) Esperou muito, por } \\
\text { horas, qualquer evento } \\
\text { demorado. } \\
\text { b) Esperou muito. }\end{array}$ \\
\hline
\end{tabular}

Para realização dos procedimentos empíricos (aplicação do instrumento), duas etapas foram realizadas: o planejamento da aplicação do instrumento piloto e a coleta da informação empírica. Para o planejamento, o primeiro passo foi a seleção da amostra, realizada conforme os critérios já descritos. O segundo passo foi o da elaboração das instruções para aplicação do instrumento. Para tanto, foi utilizado um enunciado norteador sobre a natureza do teste, a aplicação da tarefa 
e a participação do sujeito. Especificamente, os participantes foram orientados a ouvir atentamente a cada uma das sentenças e a responder às perguntas fechadas (dicotômicas) e às abertas. Foi enfatizado que para as questões abertas não havia necessariamente uma única resposta esperada. Além disso, ressaltou-se que não havia uma relação entre os itens. Após a explicação foi fornecido um exemplo. Se o participante não respondia com o sentido figurado da expressão, o aplicador explicava e oferecia respostas possíveis. O terceiro passo foi a coleta dos dados de validação, realizada pelas autoras e por participantes do grupo de pesquisa, previamente treinados para tanto. A aplicação do instrumento foi realizada individualmente, após o consentimento da direção, dos professores e da assinatura do Termo de Consentimento Livre e Esclarecido pelos participantes (adultos) e/ou responsáveis (pelas crianças ou adolescentes).

\section{Resultados}

Os dados foram analisados por meio de estatística descritiva e paramétrica, utilizando o programa Statistical Package for Social Sciences (SPSS), versão 18.

A primeira análise realizada foi a do grau de familiaridade das expressões idiomáticas dos seis itens do teste. Os resultados revelaram que o item mais familiar foi o 3 (Fazer tempestade em copo d'água) e o menos familiar foi o 4 (Sair como um par de vasos), conforme indicado na Tabela 2.

TABELA 2 - Análise percentual de familiaridade nas respostas 4 e 5

\begin{tabular}{ccccccc}
\hline EI & 1 & 2 & 3 & 4 & 5 & 6 \\
\hline Respostas "4" & 15,05 & 8,96 & 3,94 & 10,04 & 9,32 & 11,11 \\
Respostas “5" & 67,74 & 87,10 & 93,91 & 59,86 & 78,85 & 75,27 \\
Total & 82,79 & 96,06 & 97,85 & 69,90 & 88,17 & 86,38 \\
\hline
\end{tabular}

A segunda análise realizada foi a de confiabilidade dos critérios de correção estabelecidos para as perguntas abertas dos seis itens selecionados. Todas as respostas em que houve discordância de um ou mais avaliadores foram discutidas pelo grupo até se chegar a um consenso. Essas discussões não só levaram ao ajuste de cada resposta 
em que havia divergência entre os avaliadores, mas também refinaram os critérios de correção. Uma vez que o Kappa variou de 0,77 a 1,00 para as primeiras 44 questões abertas corrigidas, na avaliação de seis membros do grupo de pesquisa $(\mathrm{p}<0,001)$, julgou-se que os critérios estavam bem delineados, e as correções subsequentes foram realizadas de forma independente.

Com relação ao desempenho no Instrumento de Compreensão de Expressões Idiomáticas, houve uma diferença estatisticamente significativa entre os grupos $(\mathrm{p}<0,001)$, levando-se em conta o total de acertos (perguntas abertas e fechadas somadas). Considerando a variável idade (Tabela 3 ), o grupo de adultos apresentou a maior média de acertos $(m=10,6 ; d p=1,24)$, seguido pelo grupo de adolescentes $(m=9,55$; $d p=1,82)$ e pelo de crianças $(m=6,08 ; d p=2,10)$.

TABELA 3 - Comparação entre as faixas etárias

\begin{tabular}{c|c|c|c|c}
\hline Variáveis & $\begin{array}{c}\text { Crianças } \\
\text { Média } \pm \mathrm{DP}\end{array}$ & $\begin{array}{c}\text { Adolescentes } \\
\text { Média } \pm \mathrm{DP}\end{array}$ & $\begin{array}{c}\text { Adultos } \\
\text { Média } \pm \mathrm{DP}\end{array}$ & $\mathrm{p}^{*}$ \\
\hline Total EI & $6,08 \pm 2,10^{\mathrm{a}}$ & $9,55 \pm 1,82^{\mathrm{b}}$ & $10,6 \pm 1,24^{\mathrm{c}}$ & $<0,001$ \\
\hline Total EI Aberta & $1,83 \pm 1,08^{\mathrm{a}}$ & $4,05 \pm 1,22^{\mathrm{b}}$ & $4,89 \pm 0,96^{\mathrm{c}}$ & $<0,001$ \\
\hline Total EI Fechada & $4,26 \pm 1,33^{\mathrm{a}}$ & $5,50 \pm 0,84^{\mathrm{b}}$ & $5,72 \pm 0,54^{\mathrm{b}}$ & $<0,001$ \\
\hline
\end{tabular}

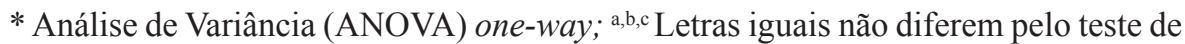
Tukey a 5\% de significância

Para todos os grupos, as perguntas fechadas tiveram maior número de acertos quando comparadas com as perguntas abertas. A análise da diferença entre perguntas abertas e fechadas por grupo também mostrou uma diferença estatisticamente significativa $(p<0,001)$ em todas as faixas etárias, e os escores foram mais elevados nas perguntas fechadas.

Quando avaliados os acertos por item, considerando as perguntas abertas e fechadas conjuntamente, verificou-se que o item com mais acertos $(85,5 \%$ e $94,7 \%$ para aberta e fechada, respectivamente) foi o número 5, que atualiza a expressão idiomática ser a metade da laranja. $\mathrm{O}$ menor percentual de acertos para as perguntas abertas $(25,6 \%)$ foi verificado no item 1, que atualiza a EI comprar gato por lebre, e o menor percentual para a pergunta fechada $(69,1 \%)$ foi verificada no item 4 , que atualiza a EI sair como um par de vasos. Essas diferenças foram estatisticamente significativas $(\mathrm{p}<0,001)$ para ambos os tipos de pergunta 
(aberta e fechada). Na pergunta aberta, o item 1 (comprar gato por lebre) foi significativamente menor do que todos os outros. Os itens 4 e 6 (sair como um par de vasos e tomar um chá de cadeira) foram os segundos com pior desempenho, sem diferença significativa entre eles. Em seguida, vieram os itens 2 e 3 (meter os pés pelas mãos e fazer tempestade em copo d'água), também sem diferença significativa entre eles, mas diferentes de todos os outros. O item 5 (ser a metade da laranja) foi aquele com o melhor desempenho e diferiu significativamente de todos os outros. Em relação às perguntas fechadas, os itens 4 e 1 (sair como um par de vasos e comprar gato por lebre) foram os que tiveram o pior desempenho, sem diferença significativa entre eles. Depois vieram as questões dos itens 3 e 6 (meter os pés pelas mãos e tomar um chá de cadeira), também sem diferença entre eles. As questões com os melhores desempenhos foram as dos itens 2 e 5 (meter os pés pelas mãos e ser a metade da laranja), que diferiram significativamente de todas as outras (Gráfico 1).

GRÁFICO 1 - Percentual de acertos nas perguntas abertas e fechadas

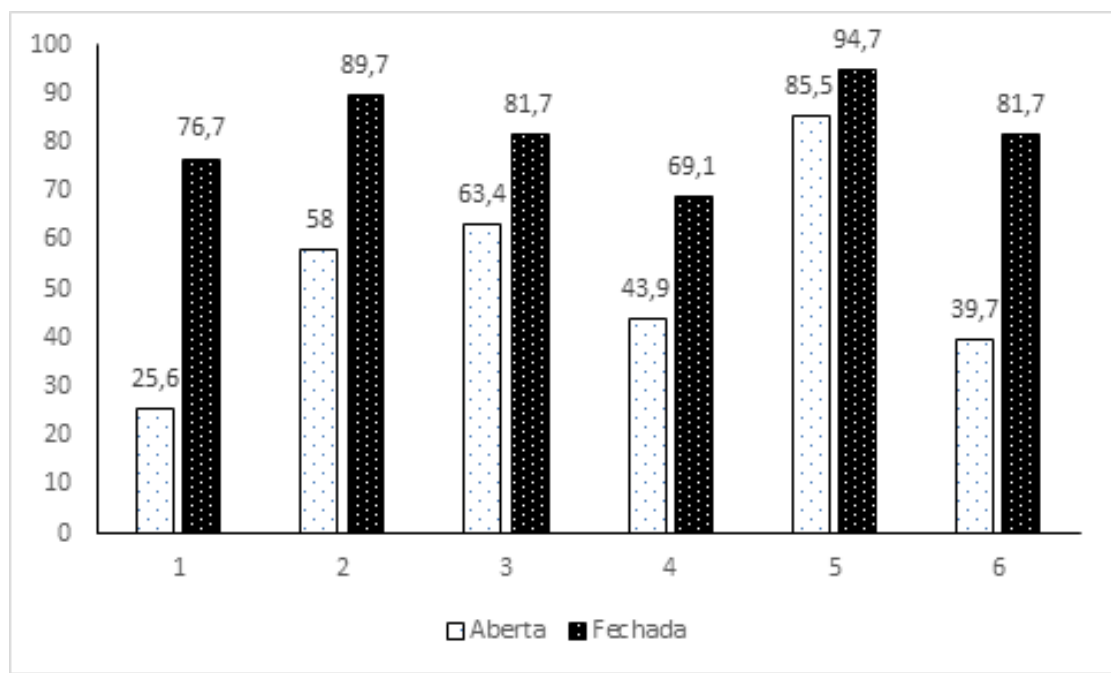

$\mathrm{p}<0,001$ para ambos (aberta e fechada)

Analisando conjuntamente os resultados da avaliação da familiaridade e da compreensão de expressões idiomáticas, verificou-se que, apesar de não ter se estabelecido uma correspondência entre os resultados dos dois instrumentos, foi observada uma tendência de os itens com maior familiaridade serem também os mais compreendidos. As expressões ser $a$ 
metade da laranja, meter os pés pelas mãos e fazer tempestade em copo d'água foram julgadas mais familiares e obtiveram os maiores índices de compreensão; as expressões tomar um chá de cadeira, sair como um par de vasos e comprar gato por lebre, por sua vez, foram julgadas como menos familiares (ainda que todas elas pareçam bastante familiares) e obtiveram os menores índices de compreensão.

Uma análise qualitativa das respostas das crianças (grupo com os menores índices de compreensão de expressões idiomáticas) para as expressões que obtiveram o maior e os menores escores sugere que a compreensão está bastante relacionada ao grau de transparência das expressões. Cabe aqui ressaltar que, conforme já descrito no método, foram selecionadas seis EI consideradas pouco transparentes pelas autoras.

$\mathrm{Na}$ EI5, item que obteve o maior índice de acertos nas respostas abertas, a maioria das crianças chegou ao sentido figurado de gostar, amar ou estar apaixonada por meio da frase Paulo é a metade da laranja da Laura. Poucas foram as crianças que não chegaram ao sentido figurado e relacionaram sua resposta com o ato de comer uma laranja, como no exemplo abaixo.

(sujeito $365-7 a)$ - Sente fome.

Ainda em relação à EI5, dois exemplos ilustram bem o quanto o significado literal das palavras que compõem uma expressão pode ajudar a chegar ao sentido figurado. $O$ sujeito 410 usa uma outra expressão idiomática, com o mesmo sentido idiomático da expressão metade da laranja, e que também tem a palavra 'metade' para explicar a primeira. Já o sujeito 411 parte do significado literal, explicitando a motivação para chegar ao sentido figurado.

(sujeito $410-9 \mathrm{a} 10 \mathrm{~m}$ ) - É a cara metade.

(sujeito 411 -11a9m) - É como se fossem completar a laranja, sentem amor.

Na EI1, que obteve o menor índice de acertos nas respostas abertas, nenhuma criança deduziu o significado figurado 'ser enganado' observando a frase Antonio comprou gato por lebre. As respostas para a pergunta fechada foram invariavelmente interpretações literais do ato de comprar um gato e/ou uma lebre, como nos exemplos abaixo. 
(sujeito $386-8 \mathrm{a} 7 \mathrm{~m}$ ) - Ele ganhou o gato e ficou com a lebre.

(sujeito 368 -9a3m) - Ele pegou um coelho.

(sujeito 365-7a) - Ele se arranhou todo.

$\mathrm{Na}$ EI6, que obteve o segundo menor índice de acertos nas respostas abertas, a resposta da maioria das crianças remeteu ao ato de literalmente tomar um chá, outras relacionaram a expressão a alguma expressão conhecida (tal como chá de sumiço) e outras chegaram mais perto do sentido figurado, conforme os exemplos abaixo.

(sujeito 381-11a7m) - Tomou um chá forte, estranho.

(sujeito 420-10a3m) - Tomou um chá com gosto de cadeira.

(sujeito 393 - 9a) - Ficou sumida.

(sujeito $373-9 \mathrm{a} 7 \mathrm{~m})$ - Ficou sentada.

Respostas como a do sujeito 373 foram consideradas incorretas, ainda que o ato de sentar esteja relacionado à ideia de esperar. Respostas com o verbo sentar só foram consideradas corretas quando explicitavam o significado figurado da EI, o de esperar por muito tempo, como no exemplo a seguir.

(sujeito 386-8a7m) - Ficou sentada esperando um tempão, esperando na cadeira.

As respostas elencadas anteriormente ilustram dois aspectos relevantes em uma análise de expressões idiomáticas pela perspectiva da Linguística Cognitiva. O primeiro aspecto é a noção de continuum, aqui exemplificada na dimensão opacidade. Assim, mesmo em expressões bastante opacas, algumas se revelam mais transparentes (por exemplo, a EI ser a metade da laranja) do que outras (por exemplo, a EI comprar gato por lebre). O segundo aspecto é a influência de múltiplas dimensões na compreensão de um mesmo fenômeno linguístico. A EI5, por exemplo, apesar de não ser considerada pelos participantes da pesquisa como a mais familiar, foi a melhor compreendida, possivelmente em virtude de seu grau de transparência.

O fato de não ter sido observada uma correspondência direta entre familiaridade e compreensão das EI pode indicar também diferenças de 
frequência de uso entre gerações. Nesse ponto, é importante ressaltar que o teste de familiaridade foi realizado somente por adultos, e o teste de compreensão de expressões idiomáticas foi realizado por crianças, adolescentes e adultos. Assim, uma EI como "como comprar gato por lebre", julgada bastante familiar por uma pessoa mais velha, pode não ser mais usada pela nova geração de usuários da língua tanto em razão de ser opaca quanto de não ser ouvida corriqueiramente, o que justifica o fato de ela não ser mais compreendida pelas crianças.

\section{Discussão}

Os procedimentos teóricos, primeira etapa da construção do instrumento aqui descrito, foram realizados à luz da Linguística Cognitiva, perspectiva que entende a linguagem como um processo dinâmico no qual as unidades linguísticas (sejam elas morfemas, palavras, expressões idiomáticas, entre outros) servem como gatilho para operações conceituais diversas que recrutam conhecimento prévio. Dando início a essa etapa, foram definidas as dimensões relevantes para as EI (familiaridade, estrutura sintática, complexidade semântica e transparência). Em relação aos procedimentos empíricos, após os ajustes feitos com base no estudo-piloto, a coleta de dados deu-se sem intercorrências, passando-se aos procedimentos estatísticos.

No teste de familiaridade aplicado, verificaram-se diferenças na avaliação dos itens (com um percentual variando de $69,90 \%{ }^{1}$ a $97,85 \%$ de respostas bastante e totalmente familiares respectivamente). Essa variação ocorreu apesar de itens presumidamente muito familiares (de acordo com buscas na internet e com o julgamento dos especialistas) terem sido selecionados. Alguma variabilidade, de fato, já era esperada, por dois motivos: o primeiro é que o julgamento sobre a familiaridade depende de frequência de uso e essa está em constante atualização; o segundo, que corrobora o arcabouço teórico adotado, é que familiaridade não é uma variável categórica, ainda que tenha sido tratada como tal para fins desta análise. Há, portanto, um continuum de familiaridade que envolve pelo menos a frequência com a qual se escuta determinado input linguístico e a frequência com a qual uma expressão é efetivamente usada. Além disso,

\footnotetext{
${ }^{1}$ Decidiu-se por não descartar a EI D (sair como um par de vasos) dada a proximidade entre o percentual escolhido para o ponto de corte $(70 \%)$ e o obtido $(69,90)$.
} 
pode-se pensar que o tipo de conceitos e a frequência das ações abordadas em uma determinada expressão idiomática (como superdimensionar um problema na EI fazer tempestade em copo d'água, por exemplo) também influenciam a frequência com que essa será usada. Assim, uma prática pouco usual (por exemplo, andar com roupas iguais) deverá levar a um uso menos frequente de uma determinada expressão (por exemplo, sair como um par de vasos) quando comparada a expressões percebidas como mais familiares (por exemplo, ser a metade de uma laranja). Em outras palavras, falamos mais frequentemente sobre eventos que observamos com mais frequência.

A primeira análise do Instrumento de Compreensão de Expressões Idiomáticas, referente à diferença entre os grupos, revelou um efeito principal de idade na compreensão dos itens. O desempenho foi melhor no grupo de adultos, seguido pelo de adolescentes e o de crianças, conforme o esperado. Assim, um maior tempo de exposição à língua levou a uma melhor compreensão das expressões apresentadas, como demonstrado em estudos com crianças, adolescentes (NIPPOLD; RUDZINSKI, 1993; NIPPOLD; TAYLOR, 2002) e adultos (NIPPOLD; DUTHIE, 2003). Esses resultados corroboram estudos anteriores que afirmam ter encontrado diferenças na compreensão de EI pelas crianças quando comparadas com adolescentes e adultos (CAIN; TOWSE; KNIGHT, 2009).

Os resultados também revelaram um efeito principal de tipo de pergunta. Em todos os grupos, as perguntas fechadas tiveram maior número de acertos do que as perguntas abertas. De um ponto de vista estatístico, de fato se esperava que perguntas fechadas com duas opções (com uma possibilidade de 50\% de acerto) tivessem um maior percentual de acerto do que perguntas abertas, nas quais não há uma pista para a resposta certa. Quando o formato da pergunta (aberta ou fechada) foi considerado, observou-se diferença estatisticamente significativa na pergunta fechada entre o grupo de crianças e os demais grupos (adolescentes e adultos). Nesse caso, apesar de terem sido controladas algumas variáveis (tais como familiaridade, estrutura sintática, complexidade semântica e transparência), ainda é possível que alguma dessas tenha influenciado esse resultado. Entretanto, se considerarmos que não somente as dimensões da expressão, mas as habilidades do sujeito estão em jogo, uma justificativa mais plausível para essa diferença é a habilidade de inferência. Essa habilidade não é uma característica da expressão idiomática, mas uma característica do sujeito, a qual se 
desenvolve com a idade, com o aumento de exposição à língua e com o desenvolvimento de capacidades cognitivas.

Apesar de a familiaridade ter sido a única dimensão investigada empiricamente, por meio de uma escala, entende-se que as outras dimensões consideradas também apresentam a propriedade de serem contínuas. Em outras palavras, tanto a estrutura sintática, quanto a complexidade semântica, a transparência e até mesmo o contexto são dimensões que poderiam apresentar alguma variabilidade em uma escala que vai de nada a totalmente aplicável a cada dimensão. Neste instrumento, uma mesma estrutura sintática foi utilizada nos seis itens, palavras e estruturas de pouca complexidade semântica foram priorizadas e foram selecionadas expressões bastante opacas, conforme o julgamento das pesquisadoras e dos juízes especialistas. No entanto, mesmo que essas dimensões tenham sido controladas, assume-se que nenhuma sentença é idêntica a outra em relação a todas essas dimensões. A influência dessas dimensões, portanto, deve ser considerada em conjunto na formulação de qualquer tarefa que envolva expressões idiomáticas, bem como na interpretação de seus resultados.

Ainda que tenham sido identificadas possíveis limitações, o desenvolvimento deste instrumento deve contribuir para suprir a ausência de propostas padronizadas para a avaliação da compreensão de expressões idiomáticas em nossa língua. O passo a passo criterioso em sua criação e validação proporcionou a verificação de evidências iniciais de validade, e os dados obtidos poderão servir como um parâmetro inicial do que pode ser esperado para cada faixa de idade estudada. Estudos futuros deverão ser realizados para que suas evidências na avaliação da compreensão sejam mais robustas e para que sejam estabelecidos efetivamente esses dados normativos por faixa de idade. Por fim, sugere-se que pesquisas sejam realizadas também com populações clínicas, que, além de contribuírem com informações pertinentes para melhor compreender o fenômeno da linguagem figurada em si, possibilitarão melhor compreensão do desenvolvimento linguístico de diferentes populações.

\section{Agradecimentos}

As autoras agradecem aos bolsistas de iniciação científica Ana Paula Anghinoni Ramos (PIBIC CNPqUFRGS), Andrea Rubert e Karoline Girardi (PROBIC FAPERGS-UFRGS) e Cristofer Tessmer (BIC UFRGS), pelo seu trabalho durante as diversas fases deste estudo. 


\section{Referências}

CACCIARI, C.; LEVORATO, M. C. The effect of semantic analyzability of idioms in metalinguistic tasks. Metaphor and Symbol, Francis \& Taylor Online, v. 13, p. 159-177, 1989. DOI: https://doi.org/10.1006/ jecp.1995.1041

CAIN, K.; OAKHILL, J.; LEMMON, K. The relation between children's reading comprehension level and their comprehension of idioms. Journal of Experimental Child Psychology, Elsevier, v. 90, p. 65-87, 2005. DOI: https://doi.org/10.1016/j.jecp.2004.09.003

CAIN, K.; TOWSE, A. S.; KNIGHT, R. S. The development of idiom comprehension: An investigation of semantic and contextual processing skills. Journal of Experimental Child Psychology, Elsevier, v. 102, p. 280-298, 2009. DOI: https://doi.org/10.1016/j.jecp.2008.08.001

FONSECA, R. P.; SALLES, J. F.; PARENTE, M. A. M. P. Development and content validity of a Brazilian Brief Neuropsychological Assessment Battery: NEUPSILIN. Psychology and Neuroscience, Washington, American Psychological Association, v. 1, p. 55-62, 2008. DOI: http:// dx.doi.org/10.3922/j.psns.2008.1.009

GIBBS, R. The poetics of mind: Figurative thought, and understanding. New York: Cambridge U. Press, 1994. 527p.

HILLERT, D. G. Spared access to idiomatic and literal meanings: A single-case approach. Brain and Language, Elsevier, v. 89, n. 1, p. 207215, 2004. DOI: https://doi.org/10.1016/S0093-934X(03)00384-5

KEMPLER, D.; SIDTIS, D. V. L; MARCHAMAN, V. BATES, E. Idiom comprehension in children and adults with unilateral brain damage. Developmental Neuropsychology, Francis \& Taylor Online, v. 15, n. 3, p. $327-349,1999$. DOI: $10.1080 / 87565649909540753$

KÖVECSES, Z. Language, Mind, and Culture. A Practical Introduction. Oxford: Oxford U. Press, 2006. 416p.

LANGLOTZ, A. Idiomatic Creativity: A cognitive-linguistic model of idiom-representation and idiom-variation in English. Amsterdam: John Benjamins, 2006. 339p. DOI: https://doi.org/10.1075/hcp.17 
LEVORATO, M. C.; ROCH, M.; NESI, B. A longitudinal study of idiom and text Comprehension. Journal of Child Language, Cambridge University Press, v. 34, n. 3, p. 473-494, 2007. DOI: https://doi. org/10.1017/S0305000907008008

NIPPOLD, M. A.; DUTHIE, J. K. Mental imagery and idiom comprehension: A comparison of school-age children and adults. Journal of Speech, Language, and Hearing Research, American Speech and Hearing Association, v. 46, p. 788-799, 2003. DOI: https://doi. org/10.1044/1092-4388(2003/062)

NIPPOLD, M. A.; RUDZINSKI, M. Familiarity and transparency in idiom explanation: A developmental study of children and adolescents. Journal of Speech, Language, and Hearing Research, American Speech and Hearing Association, v. 36, p. 728-737, 1993. DOI: https://doi. org/10.1044/jshr.3604.728

NIPPOLD, M. A.; TAYLOR, C. L. Judgements of idiom familiarity and transparency: A comparison of children and adolescents. Journal of Speech, Language, and Hearing Research, American Speech and Hearing Association, v. 45, p. 384-391, 2002.

NORBURY, C. F. Factors supporting idiom comprehension in children with communication disorders. Journal of Speech, Language and Hearing Research, v. 47, p. 1179-1193, 2004. DOI: https://doi.org/10.1044/10924388(2004/087)

NUNBERG, G.; SAG, I. A.; WASOW, T. Idioms. Language, Washington, Linguistic Society of America, v. 70, n. 3, p. 491-538, 1994.

PAPAGNO, C.; TABOSSI, P.; COLOMBO, M. R.; ZAMPETTI, P. Idiom comprehension in aphasic patients. Brain and Language, Elsevier, v. 89, n. 1, p. 226-234, 2004. DOI: https://doi.org/10.1016/S0093934X(03)00398-5

PAPAGNO, C.; CAPORALI, A. Testing idiom comprehension in aphasic patients: The effects of task and idiom type. Brain and Language, Elsevier, v. 100, p. 208-220, 2007. DOI: https://doi.org/10.1016/j. bandl.2006.01.002

PASQUALI, L. Instrumentação psicológica: fundamentos e práticas. Porto Alegre: Artmed, 2010. 568p. 
QUALLS, C. D.; LANTZ, J. M.; PIETRZYK, R. M.; BLOOD, G. W.; HAMMER, C. S. Comprehension of idioms in adolescents with languagebased learning disabilities compared to their typically developing peers. Journal of Communication Disorders, Elsevier, v. 37, n. 4, p. 295-311, 2004. DOI: https://doi.org/10.1016/j.jcomdis.2003.12.001

SIQUEIRA, M. As metáforas primárias na aquisição da linguagem: um estudo interlinguístico. 2004. Tese (Doutorado) - Pontifícia Universidade Católica do Rio Grande do Sul, Porto Alegre, 2004.

SIQUEIRA, M.; LAMPRECHT, R. As metáforas primárias na aquisição da linguagem: um estudo interlinguístico. Delta, São Paulo, PUCSP, v. 23 , n. 2, p. $245-272$, 2007. DOI: http://dx.doi.org/10.1590/S010244502007000200004

SIQUEIRA, M.; GIBBS, R. Children's Acquisition of Primary Metaphors: a crosslinguistic study. Organon, UFRGS, v. 21, n. 43, p. 161-179, 2007. SIQUEIRA, M.; DE LEON, V.; PARENTE M. A.; BOSA, C. Especificidade da compreensão metafórica em crianças com autismo. Psico. UFRGS, v. 38, n. 3, p. 269-277, 2007.

SIQUEIRA, M.; PARENTE, M. A. P.; Gil, M. Metáfora e cultura: uma interace entre a Linguística e a Antropologia. Antares, Letras e Humanidades, Caxias do Sul, RS, n. 2, p. 99-111, jul.-dez. 2009. 


\section{ANEXO 1}

\section{Escala de familiaridade}

Leia as expressões abaixo e marque com um X o seu grau de familiaridade (o quanto você conhece a expressão), considerando uma escala de 5 pontos, em que:

1 é nada familiar

2 é pouco familiar

3 é medianamente familiar

4 é bastante familiar

5 é totalmente familiar

\begin{tabular}{|l|l|l|l|l|l|}
\hline & 1 & 2 & 3 & 4 & 5 \\
\hline Comprar gato por lebre. & & & & & \\
\hline Meter os pés pelas mãos. & & & & & \\
\hline Fazer tempestade em copo d'água. & & & & & \\
\hline Sair como um par de vasos. & & & & & \\
\hline Ser a metade da laranja de alguém. & & & & & \\
\hline Tomar um chá de cadeira. & & & & & \\
\hline
\end{tabular}


